\title{
A Legal Approach to the Interaction between Sports and Human Rights
}

\section{Shafagh Malekzade Saghezchi}

Graduated In International Law, Master Degree

Shahid Ashrafi Esfahani University, Isfahan, Iran

\section{Dr. Manuchehr Tavassoli Naini}

Assistant professor, Department of law, University of Isfahan, Iran Email:malekzade.shafagh@gamail.com

Doi:10.5901/mjss.2016.v7n3p196

\begin{abstract}
Human rights are generally rights that people deserve simply because of being human, they are rights which are inherent quality and nobody can survive without them. At the international level various documents in support of these rights have been issued and the universality of it is somewhat that even the most totalitarian systems do not oppose this idea, at least literally. In one hand, the sport as a universal phenomenon affects different aspects of our life. Million spectators for sporting events and turning sport to a lucrative business have led to a phenomenon which is solely sport- based turned to a stir-maker in the phenomenon of human life. How these two universal and global phenomena interact, is the topic of our discussion. The intersection of these two phenomena can be traced back to three main areas; Firstly, sport according to international instruments is a human right, secondly, sport area in which human rights norms and standards should be applied to in the light of these principles so that athletes' human rights are preserved and promoted, and thirdly, because of the international attention and countless audience to sport, it can be a tool for the protection and promotion of human rights. The desk (documentary research) method was used to conduct this study.
\end{abstract}

Keywords: human rights, sports, the International Olympic Committee, the United Nations arbitration in sport, environment, health, foreign policy

\section{Introduction}

Sport has become a global business in the recent years in a way that it has accounted for $3 \%$ of the total transactions in the world. For instance, sport has resulted in almost $4 \%$ of the total gross domestic product (GDP) in 28 European Union countries with 505000000 people. It has been estimated over twenty-nine billion euros. Therefore, it is not surprising that the international sports organizations like the International Olympic Committee and FIFA are growing more and more powerful these days, insofar as they can lead to political implications and movements. Nevertheless, some people believe that such sports organizations are committed only to their own internal procedures, and they are not considered in international law and human rights. However, all of such organizations practically operate in accordance with international regulations and global norms of human rights. One of the objectives of the current study is to investigate how such institutionsare committed to human rights.

On the one hand, international institutions, the most important of which is the United Nations, have always considered sport to be a way of achieving the principles of human rights. The fact that the Secretary-General of the UN has created an independent institution to study sports potentials in order to achieve the UN Millennium Development Goals proves this matter, which will be thoroughly dealt with in this study. Another important problem, addressed in this study, is to identify the right to sports as one of the human rights which should be available to all human beings without discrimination. This is also proven in a part of the current study.

\section{Research Literature}

Sport and human rights are both among the areas on which comprehensive studies have been conducted domestically and internationally. Nowadays sports law is one of the majors taught at the undergraduate and higher levels. It is also publically welcomed. Nonetheless, the mutual relationship between sport and human rights is one of new areas on which 
no written literature is domestically available.

The author is more familiar with the research subject due to the participation in an annual conference held by the Council of Europe in Strasbourg, France. Each year, this conference deals with a relevant issue pertaining to the agenda of the Council of Europe. On the occasion of FIFA World Cup, the theme of the conference was sport and human rights in 2014. Having attended this research opportunity, the author could study the current stands taken by international institutions on the abovementioned subject in details. The acquaintances of international lawyers such as Mr. Black Shaw and Mr. David Paolo, working on this area, also had great effects on this study. They have kindly helped the author with different parts of this research, a fact which is really commendable and appreciable. Mr. Paolo's work entitled Children's Human Rights and Sports was very useful in writing this research.

\section{Research Necessity and Innovation}

The realization of human rights is an undeniable necessity at domestic and international levels. Investigating the potential capacities of sport, the author intends to take an effective step in this regard. Iran, known as a developing country, still faces some many inefficiencies, a large number of which result from ignoring norms defined by human rights for sport. The problem of women's participation in sports competitions, doping, and different types of verbal abuses are high costs imposed on Iran's sport. Writing such papers can draw the officials' attention to become aware of and comply with the norms of human rights, which have never been inconsistent with the general policies of the Islamic Republic of Iran, in order to create an appropriate bedrock for professional and public sports.

As pointed out in the previous part, the subject of this study is novel and unprecedented in Iran. Although many papers have been written on the relationship between sport and human rights, the bilateral interaction between these two phenomena has never been simultaneously investigated in a paper. For instance, the report, published by UNICEF Study Group, investigated the impacts of sport on the development of human rights including the rights to education and security in details. Moreover, the papers, written by experts such as Mr. Black Shaw who is one of the umpires of the International Court of Arbitration for Sport, dealt with the norms of human rights pertaining to sport extensively. Among them, there is a paper entitled Opportunistic Marketing and the Right to the Formation of Communities, which investigated the process of exchanging footballers from the perspective of human rights. However, the current study dealt with both sides of the relationship; in other words, the interaction between two areas. Therefore, if this study is no unprecedented, it is rare.

Do sport and human rights, known as two universal phenomena, overlap with each other? Why are the norms of human rights applicable in the world of sport? Why is sport thought of as a tool to maintain and promote human rights?

Sport and human rights are both two universal and extensive phenomena intersecting each other at three particular points. First, sport is a category of human rights. Second, sport is an area to which the norms and standards of human rights should be applied. Third, sport can be used as a tool to develop human rights.

The necessity of maintaining athletes' rights in sports fields requires that sports organizations and institutions should be committed to the norms and standards of human rights while codifying their rules and regulations.

The global grace of sport, live streams of competitions on public media, and the countless number of audiences made international institutions benefit from the latent capacities of sport to maintain peace and improve human rights.

\section{Research Objectives}

Sport and human rights are broadly connected. When I was talking with sports people about the relationship between these two areas, a very interesting question arose. What is the relationship between human rights and sport? The most important objective of my research was to show this relationship to the sports community. If it is fulfilled, athletes realize that the rules of the Olympic, FIFA, and other sports federations put some responsibilities on their shoulders by a higher law named human rights. Then these rules let them benefit from the protection against violations.

Given the capacities of sports fields and also considering various violations of human rights in the world, it can be stated that the global community has not been able to exploit 100\% sports potentials yet. The author has tried to make suggestions so that the maximal capacities could be used to fulfill human rights.

In media, the problem of sport and human rights are rarely covered in the world, especially in Iran. In the global community, sport is more a money-making tool rather than being used for the physical and mental excellence. Presenting a new definition of sport and defining a framework for it with respect to the standards of human rights can moderate the commercial viewpoint and stop the continuity of immoral behaviors which are against human rights in sports fields. The author has tried to prove the constitution of sport on human rights to introduce a new look at it. 


\subsection{The status of human rights in the sports area}

Sport as a universal phenomenon has changed different aspects of human life. Converting it to a local business to earn the highest wages has led to attract the attention of human rights activists in the area. According to universality of human rights in today's world, sport cannot remain indifferent to human rights standards. The need to protect the rights of athletes, especially those athletes that due to the specific conditions are placed in vulnerable groups, makes the sport to be of human rights. In this context, after reviewing the status of vulnerable groups, some common phenomena in the sports world will be explained that their occurrence leads to widespread human rights violence and at the end, in a detailed part the right for athletes to an access for a fair trial with will be examined.

\subsubsection{Protection of vulnerable groups in sports fields}

Vulnerable group refers to a group of human population that because of the some peculiarities of human rights is subject to violence by other individuals and institutions. The vulnerability of these groups has caused international organizations; especially the UN to prevent violations to the rights of hundreds of international conventions and declarations issued and ask the countries to find a way to compensate for social inequality relative to these people.

\subsubsection{Women in sports fields}

Women are comprised half of the world's population. So it seems inevitable that women influence social relations. And also, the difference in their physiological characteristics makes them more vulnerable than men.

United Nations efforts to support women have successfully done. Declared 1975 as the International Year of Women, introduction of decade from 1975 to 1985 as the Decade for Women, ratification of Abolition Convention on all Forms of Discrimination against Women in 1975, an international conference in Beijing (in 1994) were of the UN's actions supporting women's rights.

Women, because of the numerous socio-cultural reasons, historically have not had enough opportunity to prove their competence to participate actively in sports, but the fact that women are ideal in sports and express social landscape of a society, are undeniable. (alkhooli, 1381; 102-103) When talking about women in sports arenas, the first and most important issue is gender equality. Something that is the center of all women's rights movements and many international documents.

The issue of gender equality in the field of sports has been from the beginning and has been rising. Women are not a minority in terms of numbers because they constitute half of the world's population. But the cultural, religious and social issues have led to treat them as a obedient and worthless creatures. Their place in games and sports shows this worthless. To compensate for this disparity, it is necessary that the women try to enjoy their equal rights to work and sanctions for serious violations design. (Mertoos, 1382; 125-145)

\subsubsection{Children's sports fields}

When women and children sport they enjoy many benefits such as health. Sport is a phenomenon that its positive characteristic is more than negative characteristic. But, scientific evidence shows that young athletes' healthy body image can lead to disaster. Sport is part of a healthy and balanced life but sometimes, especially in professional and competitive sport, the balance of physical needs of competitive athletes, especially young female athletes is disturbed that brings serious consequences.

Abuse and violence against children in sports arenas takes many forms. Imposition of intensive training beyond children tolerance for success in sports arenas, insufficient rest, diet and intense sport to avoid hypothyroidism corporal punishment of children and athletes are of physical forms of violence. However, violence can be sexual or psychological. Sexual and abnormal coaches' look at children athletes, touching or forced sex and rape against children occurs frequently among sports clubs.

With the arrival of a child into the realm of professional sports, the sports world economy issues will engage him. A professional athlete can be considered a source of family income, can be used as a tool for economic promotion, and these issues make a child athlete to become a child labor. Child labor catches considerations in many international instruments. Article 32 of the Convention on children Rights was set to child labor and asked the State Members to determine the minimum working age, hours of work and mechanisms to punish those forcing them to work. In addition to two resolutions Nos. 182 and 138 of have set to child labor matter and the government has been asked to refrain from 
hiring children from dangerous and risky works. Today, many athletes especially soccer players under 18 years in different parts of the world are responsible for providing subsistence for the family and in this respect the possibility of training them becomes impossible.

One of the most successful experiences in the field of legislation concerning the code of conduct and good practice for trainers in Ireland in 2001 was approved. The charter states that every citizen as an adult has responsibility to protect children from harm and compliance of government in providing an appropriate response and report on the risk of harm to children. This responsibility is true wherever there is a risk of damage to the people, both inside and outside the sports arenas.

\subsubsection{Disabled in sports fields}

Physical or mental disabled people due to certain circumstances form a part of vulnerable groups. Governments and international institutions attention to persons with disabilities gives them the opportunity to not only achieve the highest possible health level, that is an inalienable right for all, but also to experience the rehabilitation of independent vital organs. However, in most countries, particularly less developed countries, disabled people are subject to discrimination.

The sports movement and development in the 21st century was due to the fact that sport is considered costeffective means to promote human rights and international development. In one hand, the importance of sport in building and maintaining health is no secret today. Sport can lead to physical and mental health of athletes. The fact about the athletes with different physical disabilities and certain physical conditions is true. (Bhuranendra, 1999; 226)

Sport can provide for people with disabilities the opportunity to participate in society, to restore their lost confidence and provide an opportunity for employment of these people. The Olympic ideal that everyone is entitled to do sport without any kind of discrimination and be healthy is not only for healthy people without a disability. Sport is a human right and holding sports games for people with disabilities can realize this right.

Sport has the potential to reduce the government economic burden for the disabled and make them to become as a generating part of the economic cycle. This eventually leads to the conclusion that society burden lower cost at providing health care.

International Paralympic Committee is the international institution of sport management for disabled people that is the coordinator and organizer of the summer and winter Paralympic Games, and other professional sports competitions for the disabled. International Olympic Committee to hold sports competitions in 13 disciplines, at different levels of sport develops opportunities for persons with disabilities around the world. To enabling Paralympic athletes at achieving excellence in sport and spark of the world, the International Paralympic Committee's goal is to create global opportunities for empowerment. (Vision and Mission, 2004; 5)

\subsubsection{Hooliganism, doping and racism in sport}

The incidence of some events in the world of sports has led to widespread and gross violations of human rights. So, sports organizations are therefore expected to operationalize human rights standards, to prevent the occurrence of these events.

\subsubsection{Hooliganism}

Conflict has affected large sporting events in recent years. Violence in sport mainly is seen in the 60s and 70s with new forms in English football. When sporting violence takes a new form of violence and turns from violence of amorphous masses to violence by organized and pre-planning groups. Organized and planned sports violence are referred to hooliganism. This term is used to describe a wide range of conflict and violence that may occur at various levels among spectators or players, or both, although this term is primarily a football term.

This word is referred to fanatic, violent and extreme sports teams that do not fear anything, including murder and damage to public property in order to support their team. Hooliganism in English soccer is referred to the behavior of extremist groups and gangs that in every situation have a particular culture. These prejudices, both inside and outside of the stadium have been seen and have caused many tragic disasters. This term for the first time has been applied by police in London in the summer of 1899 at Daily News and the proof case is a man named Patrick Hooligan Irish topper who had presence in all the street riots that time. According to another one, a family of the same name in the 19th century lived in very harsh and brutal methods. Then families who treated like that family are called Hooligan. Nowadays most of the big teams are Hooligans. (Cooper, 1389; 24 and 25) 
Sports violence in stadiums or hooliganism is of common incidents that could even lead to violations of the right to life of players and spectators. Violence is told the flash and explosion-like power that appears threatening, harmful and sometimes fatal. In social aspect, violence is defined by using force or power in a destructive way by institutions or social identities in order to achieve the institutions and identities defined ends. In the words of Thomas Aquinas in non-violence, the individual's free will of violated is overwhelmed. (Paya, 1389; 36)

When sport is recommended for health and wellness, mixing sports and violence hazard with physical, social and psychological conditions of athletes and creates a contradiction. The aim of the sport is to create health in order to live healthy which will be at risk with the emersion. Necessity of focus to human rights norms in sports requires designing a strong legal mechanism for security and the realization of the right to life to prevent this phenomenon. Sports violence is considered at three levels; violence of fanatical fans in following of their favorite team compete against each other and sometimes to public property, violence against sports players and spectators of violence between the two teams.

Hooliganism climax in the 80s and 90s in the UK led to wide practical measures by the government, clubs and sports federations to control violence in sports arenas. This work is a very successful model for other countries to follow and to implement the mechanisms of sport to reduce violence. But the real thing at this stage is to answer this question: how human rights and hooliganism are coincided and how this phenomenon which is not so rare is related to human rights? The answer to this question lies in the right to life. Other rights are the right to life due to stop it, is the foundation of all human rights. This right because of its fundamental role has been known as the paramount right. Among human rights in schools and religions are accorded the right to life is like a spring that other rights arising from it. Every human right for every human being and any perfection an individual needs to reach are dependent to life. Anyone who wants to reach dignity and human perfection through the stages and climb the last rung of ascendancy should be alive. Violation at sports overwhelms individual's right to life and physical integrity. Sport means fitness, sport, PI work and gestures in the direction of health and strength. (Rabbani, 1345; 1345)

\subsubsection{Doping}

International Olympic Committee defined doping as: using materials or the way which are harmful to health, but at the same time improves athletes' performance. In recent years turning sport to one of the most profitable businesses in the global sports caused professional athletes to have increasingly more willing to use the materials. However, the expanded use of these drugs not only hazards athletes' health, but causes the collapse of the concept of fair play that is the ideals of the Olympic Movement as well.

Control and anti- doping actions are performed mainly by sport organizations. Further, paragraph 8 of Article 2 of the Olympic Charter refers to one of the most important roles of the International Olympic Committee. The committee's role in promoting fair play and anti-doping actions, anti-doping actions at the highest levels is carried out by the AntiDoping global organization which is placed in Montreal, Canada. International sports federations such as FIFA and the International Olympic Committee of FILA are also members of this organization.

Conflux of doping and human rights can be traced to two main areas; the first doping is violated the right of athletes health. In the second place, the claim of using performance-enhancing drugs by athletes and the competent authority should be examined in the course of a fair trial, and this athletes' right to a fair trial will be raised. (Shoja, 1387; 74)

The importance of doping and athletes' health is to the extent that several international documents have been passed with the same issue by sport and non-sport organizations; including the master resolution adopted by the United Nations Educational, Scientific and Cultural Organization on 5 October 2003. The resolution of the element of the United Nations to plan their definitive adoption of a convention to combat doping, that serious obligations are imposed on its Member States in this regard is announced. (United Nations General Assembly, 2003)

Anti-Doping global continuity to conflict with it led to approval a convention called the International Convention on Elimination of Doping. This Convention was adopted on 19 October 2005 and has been operational since 1 February 2007. At the preamble of this Convention it is mentioned that the need to protect the health of athletes and that doping may endanger their health and with regard to this that use of performance-enhancing drugs is a form of cheating that the future of sport and sport ethics face risks, hence, members of the United Nations Educational, Scientific and Cultural Organization have decided to ratify this Convention.

\subsubsection{Racial discrimination in sport}

Non-discrimination makes free an individual whose ability and innate differences and full talent are in danger. 
Discrimination as explained in international documents is referred to denial of fundamental rights and human rights adapted to groups of people who are deprived of it. Features several bars discrimination based on race, color, sex and religion. Although the attributes that are listed in no way are not finished and appear in the new forms of discrimination. (Bhuvanendra, Ibid; 28)

The principle of equality has been mentioned in various international documents. Article 26 of the International Covenant on Civil and Political Rights and Article 3 of the Convention on social, economic, cultural, and Article 7 of the Universal Declaration of Human Rights are set for this principle. According to these articles, the principle of equality is protection of all people without any distinction and the principle of equality before the law to do not mean absolute equality, the equal treatment of people regardless of the specific circumstances of the individual. But it means relative equality and the need to ensure equality is providing equal opportunity to realize human rights. (Shaygan, 1383; 172)

Sport as a universal phenomenon in the contemporary world is the issue of human rights. Explaining that all true principles of human rights should be applied in sports processes. Petros Ghali, former General Secretary of the United Nations at International Year of Sport and the Olympic ideals (1994) expressed: "Olympics invites individuals respectfully. There is a normal relationship between ethics and principles of the UN Olympics." (Dept. of Public Information United Nations, 1994; 8-29)

\subsubsection{Investigating the International Court of Arbitration in Sport, and the right to a fair trial}

The right to a fair trial is one of Human Rights. A right that is rooted in equality. In a fair trial, the not being guilty of the assumed accused is called the principle of innocence. Article 11 of the Universal Declaration of Human Rights says: Everyone charged with a criminal offense has the right to be presumed innocent until it is proved guilty according to law in a public trial at which all the guarantees necessary for his defense be available.

\subsubsection{Sports disputes and familiarity with the Court of Arbitration in Sports}

As long as the sport was only fun, sport disputes were not serious. Along with maintaining its fun framework, at first in the West and then to across the world, public interest to sport led to economic thinking, and activities that previously were used only for recreation and leisure has now become a source of funding. Competitions, ticket sales, advertising, sport, formation of international sports organizations, the media and etc made sport out of its traditional structure and became a basis for economic activity. Sports clubs took the form of business corporate as organized symbols, and sports became a profitable business. A phenomenon that is combined with economy; in the first stage it requires careful regulation and in the second stage it requires to resolve disputes arising from its institutional needs. Sports disputes born of mixing sport and business should be resolved on an impartial organization, and on a basis of fairness; the disputes that may encounter athletes human rights with serious challenge.

In accordance with Article 42 of the Olympic Charter, in Iran, all disputes relating to the sport are resolved on the basis of General Assembly the Commission on sports rights and the Commission will act by the approval of the General Assembly as an institution of discipline, mediation, reconciliation and judgment. All disputes and complaints first are discussed and solved at the Sports Rights Commission. The final decision issued by the Commission on Human Rights on the dispute to the Court of Arbitration for Sport appeal procedure can be used exclusively to send to international sports court; In this Court, the dispute shall be resolved certainly based on the relevant provisions of the arbitration field. The time limit such appeal is twenty-one days after receiving the decision issued.

\subsubsection{Investigating the Court of Arbitration in Sport and the International Council of Arbitration}

Investigation of sport disputes is done at "CAS" according to the statute. In order to resolve Sports disputes through arbitration and mediation, two institutions have been established; The International Council of Arbitration in Sport and Court of Arbitration in Sport. Disputes where a federation, association or other sports organizations are a member, on the basis of this statute are subject to arbitration. Of course, only if the laws or regulations of such organization or a specific agreement was stipulated. (Statutes of ICAS and CAS, A. Joint Dispositions, s1)

The goal of "ICAS" is to facilitate the settlement of sport disputes through arbitration or mediation and protect of the independence of CAS and rights of the parties. The Council is also responsible for administration and finance matters of "CAS". (Ibid, s2)

"CAS" has a list of verdicts and provides the conditions for resolving sports disputes through arbitration ruling panels of one or three sentences. "CAS" has a list of mediators and provides the conditions for settling sport dispute 
through mediation. Mediation procedure is controlled by "CAS". (Ibid, s3)

The Court of Arbitration investigates the disputes in two forms. In typical arbitration, commercial or business could be an issue that may be referred to other courts, but because of its association with the sports theme it has been proposed to "CAS". Arbitration appeal is associated with the decisions of the disciplinary committees, the same parts and the sports federations. The Subject of arbitration appeal is challenging the decisions taken by sports federations, Provided that the provisions of relevant Federation recognize the competence of "CAS". These procedures are usually reserved for cases of doping. Nowadays, all responsible institutions at international sports are part of the Olympic Movement, and many other federations recognized the competence of "CAS". In order to judge better in the world of sports, "CAS" has provided methods such as mediation and counseling for sports audiences. If the practice of mediation and consultation fail to end the disputes, the determination procedure of special circular is another form of the procedures proposed by the "CAS". The Special procedure is adopted to facilitate rapid decision-making during the major international games like Olympics. (Shabani Moghaddam, 1393; 19)

\subsection{Sport as a tool at the service of human rights}

Sport, because of global interest has the potential to create social, economic and political changes. This feature of sport in recent years has attracted much international attention.

\subsubsection{Sport and development}

In the sports arena, the developing world has only attained a moderate level and the rest of the world is backward because of little capital and funds. To deal with the arrears the International Olympic Committee has established fan Cohesion Fund to support developing countries, Countries that attracted an important part of the sport international attention. In these countries lack of financial resources has led to further efforts for development in the field of sport done. In this regard, to regulate this flow, the International Olympic Committee for consultation and technical assistance to developing countries in the field of Youth and Sports has established an international headquarters that it is the headquarters of the International Olympic development work. (International Olympic forum for development)

\subsubsection{Sport and protection of the environment as the common heritage of humanity}

The environment apart from the nature, apart from the society in which man lives, is inconceivable. Environment is everything that surrounds an organism or a combination of both natural and human systems. Human like other species of the components of the global ecosystem, always is in interaction with the environment and transfers it in the form of a global transformation. Today, the land is undergone rapid population growth along with increased use of fossil fuels, especially in the industrial societies put increasing and concerning pressure over the environment. Protection of the environment as a social problem is important for governments and nations, because environmental degradation by humans has created serious problems and his future life is in danger. (Abdoli, 1386; 166)

Focus on environment is one of indicators of development in each country, and sport was one of the phenomena that had been proactive in protecting the environment. The link between sport and a clean environment is one that deals with human health. Many sport activities are in open air, and other activities that are not in open air directly or indirectly use the existing air. The International Olympic Committee was been Pioneer at sports activities to protect the environment, because the Olympic movement is based on the health and welfare of mankind and societies. Sport and environment topics from the early 1990s were discussed and taken into consideration more than ever in the Olympic movement. (Abdoli, the same, 167 and 168)

\subsubsection{Sport and health}

Having health is the foundation on human rights and forms a part of the peace process. Article 25 of the Universal Declaration of Human Rights announces the entitlement of the health, welfare, medical care and social services. In accordance with Article 55 of the UN Charter, the settlement of health issues and problems associated with it are some of the topics that were emphasized in order to create conditions of stability and prosperity and peaceful relations. Sport and Physical Education is essential for a long life. Sport and game increase health, well-being and life expectancy and decrease the risk of non-infectious diseases such as heart disease. Physical activity and continuing play are necessary for development and physical-mental-social enhancement. The important role of physical education has been proven by 
the fact that children who participate in sports are as good as adults. Sport also has a positive effect on mental health causes valuable social relations. The global Health Organization in 2004, taking into account the importance of the relationship between sport, physical education and health has provided global guidelines on diet and physical education and health provision and has adopted a resolution in relation to health promotion and techniques of healthy life. Each of these documents demonstrates the importance of beginning sport from childhood. In 2004, the Joint United Nations plan on AIDS, signed a memorandum of understanding with the International Olympic Committee to development more the international sports at conflicting against infectious diseases.

\subsubsection{Sport and its economic importance}

Economic system is a system that pivots by production, distribution and utilizing wealth. It is one of the most important human systems that is involved in creating social structure as a whole. An economic system is the lifeblood of the economic and social development and also the most important support of it, and at the relationship between economic activity and other activities and expresses the symbols related to the social aspects of the human. (Alkholy, same; 127)

Sport is a big global business that has 3 percent of the global trade volume. In countries of European association which have a population over 505 million EU 3.7 per cent of GDP is allocated to sports. Among the 29 members of European association, sports have engaged 5.4 percent of the workforce. (International Institute of Human Rights, 2014; 45)

Sport can enhance economic development through various ways. It can increase individuals' ability at production and generally workforce through promotion of health, wealth and conflicting with diseases, and decrease family losses related to disease treatments. This matter in turn leads to lower health costs of community members. Additionally, sport gives opportunities to community members to develop and learn skills that ultimately lead to an increase in employment and household income. Sports, workshops, sports and sport events can be directly or indirectly create employment and job opportunities, and ultimately lead to economic growth.

\subsubsection{Sport and policy}

Nowadays, sport influences all human life aspects. The main feature of this phenomenon is strengthening national solidarity, exchanging cultures and creating friendship between different societies. But throughout the history, we are faced with so many people using sport capacity use sports fields as a place for expressing demands and whishes. Sport capacities and sport phenomenon are not away from the perspective of politicians. In many cases, victories in sports arenas are the source of legitimacy of political. However involvement and intersection of sports and politics not desirable for everyone and have some opponents.

\subsubsection{Pros and cons of politicization of sport}

Generally, government interference in the sport is to encourage young people to participate in social activities, promoting health, promoting social and cultural norms among the public, academic achievement and cultural development of athletes and other participants from each group, the creation of national and international status strengthen the concepts of fair play, international trade, economic development and increase the amount of support from political leaders and government. (Coakley, 2004; 3) Furthermore, in numerous cases, sport has changed into social groups for expressing wishes. However, intersection of these two phenomena is not very appealing. But the main question is whether the separation of sport sports and politics is possible and desirable or no?

Policy appears in its various forms in the sports arena. Sometimes the face of this intervention is naked, such as when Iranian athletes refuse to deal with the Israeli athletes and sometimes the intervention has hidden face. Such as secret transactions rated to win the World Cup. Sometimes this happens by governments and sometimes by people like Azeri people's support of Tractorsazi for sending this political message to sovereignty that we object to our neglect to our native language. Having these forms, Can the alcohol cut the policy from sport areas or not? Among the experts this question can be answered in two ways.

The first group is those who are opposed to intervention in sports politics; supporters of this approach believe that politics may creates disaster by entering to sports arena, so, their eclecticism should be avoided as much as possible.

On the other hand, some say that although the slogan of separation of policy and sport looks good, even in democratic countries today intervention of sport from politics is undeniable. These people believe that when a national team participates in the World Cup, It bears his national identity. National anthem and raising the flags of countries indicate that sports and politics somewhat inevitably overlap each other. 


\subsubsection{The role of sport in changing policy natures of countries}

That sport can be effective in the nature of a political system, in the first stage, it seems far-fetched. A careful reading of the history of sport, we will discover that this phenomenon and to what extent people in the struggle against dictatorship and transition to democracy could play a role.

For example, the FIFA awarded the hosting of World Cup 1978 to Argentina and in the early 70s and in 1976 the Argentine military coup took power in a coup. In Argentina it was normal. New generals' moods were not good and happy. They launched a dirty war against their country. One of their favorite methods was to toss opponents from aircraft into the River Plate stadium. (Cooper, 1382; 320) Ultimately World Cup was held in Argentina because of large costs to prepare the stadium that was used for the closure of all construction projects across the country, and widespread corruption, that during the project was promoted.

\subsubsection{The role of sport at foreign policy}

In the field of foreign policy mixing sport with politics appears more. Generally, any behavior in sports arenas reflects the performance of the government and may reflect the political position of the states. Despite all negative aspects and the political exploitation of the sport, the role of it in strengthening relations between countries is not secret. So that at global level, sport is used to settle the international conflicts. Because the sport is a ready environment and the factor of mitigating conflicts and is considered a natural entry for international meetings. For example, holding champion between former Federal Germany and the former Soviet Union which was held in the city of Augsburg and helped to reduce tensions between these two countries. In addition, many countries uses their world-renowned athletes as a diplomat or representative of their countries in international committees or as a traveler ambassador. For example, some of them are responsible for unofficial diplomatic mission like indirect advertising for their countries. This method is common in the US and China. (Akhavan Kazemi, 1378; 122-128)

Furthermore, in many cases, the sport was effective in improving political relations and broke the taboo of resumption of diplomatic relations between the countries that were been under tension for many years in their relationship with each other. Historically, sports have had a great share in the settlement of problems between the parties. It is rooted in the nature of sports. (Alkholy, same; 125)

\subsubsection{Sport and peace}

Peace and security is one of the main objectives of the United Nations and the need of human societies. In this regard, social tools and phenomena that enable the international community to fulfill this purpose are quite important. Documentary evidence suggests the increasing importance of sport in public life. Hence, the sport has appealed more and more attention of the international community and the peoples of the world seek to take advantage of this phenomenon for peace and security. History shows that the use of sport for peace has not been unprecedented. If sport is a means to facilitate peace between nations, peace and tranquility of it will be stable. Sport can be as a way to convey a message of peace and influence the relations between governments, and also international organizations including the United Nations can benefit from the capacity of the sport as a way of peaceful settlement of disputes.

The historical memory shows the great efforts to achieve this goal and establishing a lasting peace. In order to achieve these goals, various methods and tools were used, that sport is one of these tools, which can serve human, and different nations have benefitted from it with various reasons such as survival, social power, military readiness, health, development, education and peace citizens. (Liker, 1384; 5-20)

Ways of peaceful settlement of disputes has set for in Article 33 of the Charter of the United Nations. The important point is the possibility of using other peaceful ways to end international conflicts. A matter that makes it possible for the phenomena such as sport to be useful at solving international problems due to their inherent properties. The importance of peaceful settlement of disputes led to passing resolution 2625 the United Nations Declaration on Principles of International Law concerning related to Friendly Relations and Cooperation between the states. According to this resolution, UN member states are required to resolve their differences by resorting peaceful ways.

\section{Conclusion}

From ancient times when the embryos of sport were shaped at the foot of Mount Olympus in Greece, humanity is concerned with sport. Today, except from sporting events, there is no other event where representatives of different 
nations with conflicting interests interact with each other at this level, and this is a sign of the importance of sport in the stressful world today. increase in sports audience, increase of the volume of trade exchanges in sports and live broadcasts of all sports competitions and sports events in the mass media have pushed the sport away from being solely fun and leisure activity and give it the potentials of event-making and influencing human life,.

The relationship between sports and human rights is extended, complex and evolving. Sports and human rights have constructing interaction with each other as global phenomena. All sports and physical education are human rights. Presenting sport as a human right brings different responsibilities to the States. In this regard, they shall, in the first stage, provide the terms and conditions for access to sports facilities without any discrimination. In second stage, they are obliged to maintain the independence of institutions and sports organizations, the politicization of sports in the upstream, and at the end, they are charged to monitor to ensure of enforcement and performance of human rights at institutions and organizations to the athletes These means commitment to respect, and commitment to fulfill the obligation to protect the right to sport citizens by the governors.

The second area is human rights relation with sport to protect the human rights of athletes at Sport arenas. Today, sport organizations cannot be indifferent to international human rights. Athletes' activities, national and international actions are like any other human life area is related to human rights. In this context, the organizations shall consider standards and norms of human rights at codifying laws and regulations, which leads to talking about the protection of vulnerable groups in the sports fields. The needs for gender equality between male and female athletes, the need to anticipate the protective measures to children and create equal opportunities for disabled athletes are commitments of the sports institutions and agencies.

Its third area, the relation of human rights with sport concerns the role of sport in maintaining and promoting human rights. because Sport for being the potentials of global interest and millions or even billions of spectators can serve human rights and transform the world to a better place to live accordingly. This feature of sport has not kept away from the international institutions, organizations, governments at the global level and civil society at the national level. Sport can accelerate the process of development and modernization. Athletes needs of clean air and environmental and environment advertising by athletes, and sport events are the factors that contribute to sustainable development in environmental dimension. Sport can provide the context of a developed society by reducing costs related to health and non-communicable diseases such as cardiovascular disease.

In today's world, the relationship between peace and human rights is undeniable. In this regard sport as a tool at the service of human rights can become a tool for creating and maintaining peace. The domestic and international disputes before the war, in a narrow sense, have brought challenge for humanity. In this respect, sport can play a key role in peace building.

\section{References}

Persian sources

Akhavan Kazemi, M., sports and politics, the Olympic Quarterly, 1 and 2 (13) 1378 spring and summer.

Paya, Ali, epistemic relativism and social violence on the ground, the magazine Kian, 1389, \# 47

Pele, Allen and others, public international law, translated by Hassan Habibi, Tehran, information dissemination, 1382.

Tamoshat, Christian, human rights, translated by Hossein Sharifi Tarazkohy, Tehran, published in 1386.

Alkholy, Anwar Amin, sport and society, translator Reza Sheikh, Tehran, the publisher, 1381.

Es, F, et.al, strengthen international cooperation in the field of human rights, Tehran, Tehran University Press, 1383.

Shoja, J., research and development of nanotechnology and Right to Health, magazines legal research, Autumn and Winter, 1387, No. 14.

Abdoli, updates, psychological and social foundations of Physical Education, Tehran, early publication of the book, 1386.

Mertoos, Julie, education, human rights of women and girls, Fariborz Majidi translation, Tehran, mother spanking, 1382

Naserzadeh, H., human rights notices, Tehran, Press Institute (SID), 1372.

Shabani Moghaddam, Saturn, the International Court of Arbitration in Sport, Tehran, City of Knowledge, 1393. 